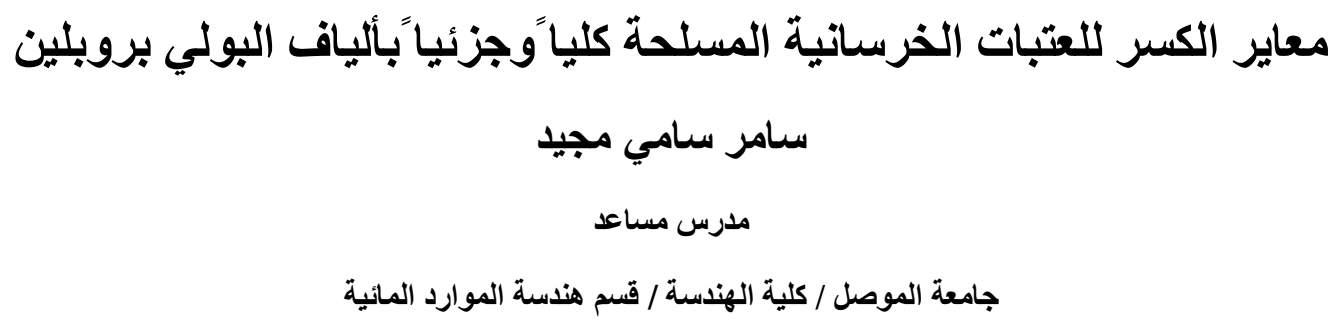

الخلاصة

إثتمل البحث على دراسة عملية لبعض الخصائص الميكانيكية التي تضمنت مقاومة الإنضفاط ومقاومة الثد الإنشطاري

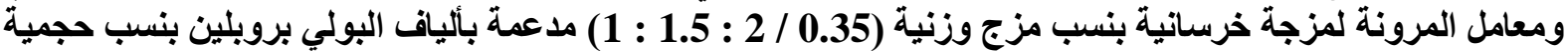
(0.25\%, 0.50\%, 0.75\%, 1.0,\%, 1.25\%)

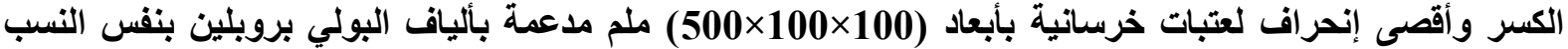

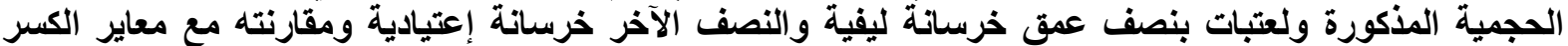
وأقصى هبوط لعتبات خرسانية إعتيادية

\title{
Modulus of Rupture of Fully and Partially Reinforced Concrete Beams With Polypropylene Fibers
}

\author{
Samer Sami Majeed \\ Assist. Lecturer \\ Mosul University / Engineering college/ Department of water resources engineering \\ samir_sami63@yahoo.com
}

\begin{abstract}
In this research an experimental study was conducted to explore some mechanical properties such as compressive strength and splitting tensile strength and modulus of elasticity of concrete mix with weighted mixed portions $(1: 1.5: 2 / 0.35)$ reinforced with polypropylene fibers by $(0.25 \%, 0.50 \%, 0.75 \%, 1.0 \%, 1.25 \%)$ as volume percentage comparing with normal concrete. Research also contain testing modulus of rupture and maximum deflection of polypropylene concrete beams with dimensions $(100 \times 100 \times 500) \mathrm{mm}$ with the same volume percentage and concrete beams with half depth fibrous concrete and the other half normal concrete and comparing with the modulus of rupture and maximum deflection of normal concrete beams.
\end{abstract}

Keywords: Compressive and Tensile strength, Deflection in beams, Modulus of elasticity, Modulus of rupture, Polypropylene fiber. 


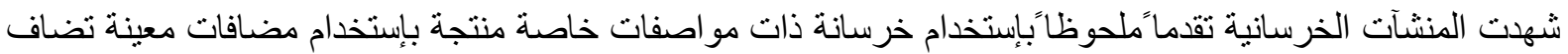

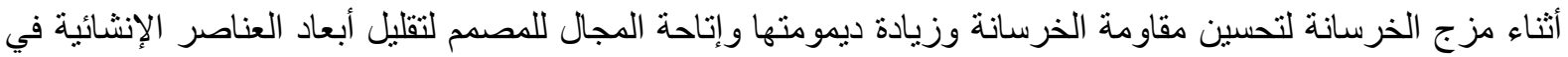

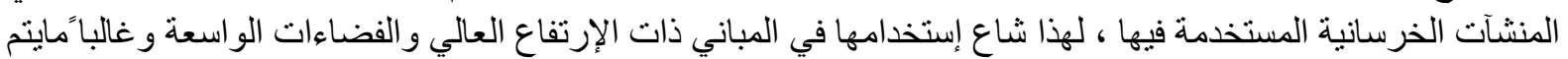

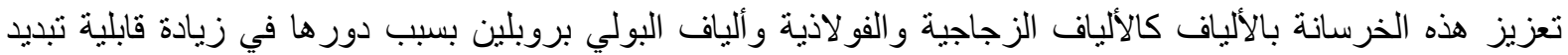
الطاقة وتقليل التشققات وتحويل الفشل في الخرسانة من فنشل قصف مفاجيء إلى التى فنل مرن تدريجي وتحسين مقاومة

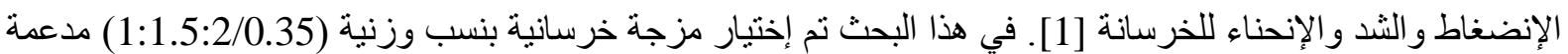

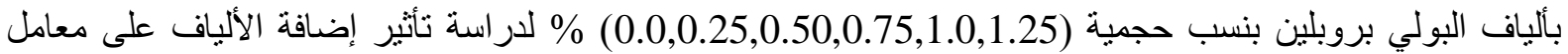

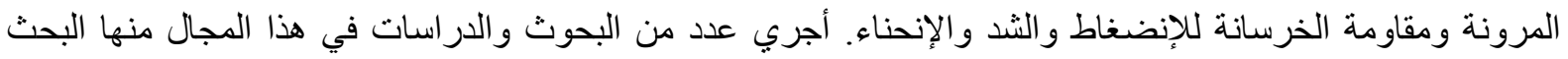

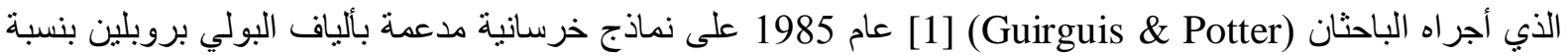

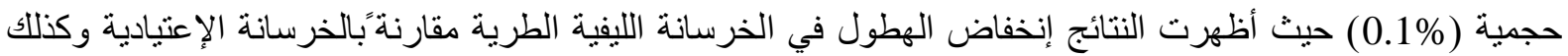

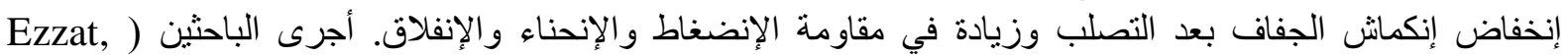

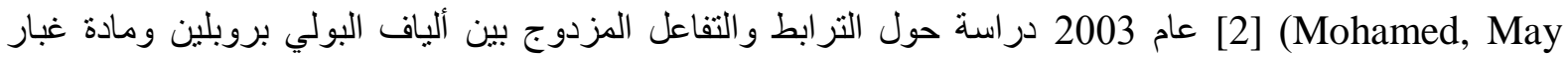

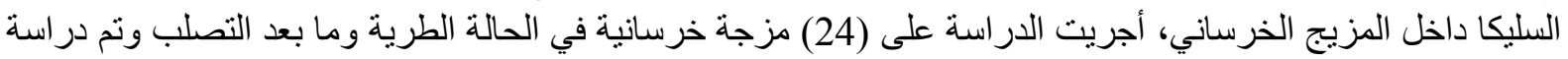
الديمومة الكيميائية والنفاذية و أنثكال التشقق الحاصل في الخرسانة ولظروف بئئية مختلفة، كانت النسبة الحجمية للألياف

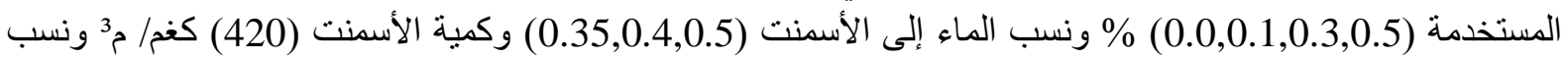

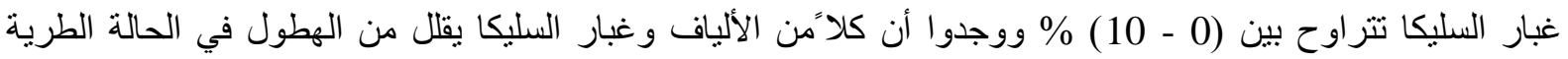

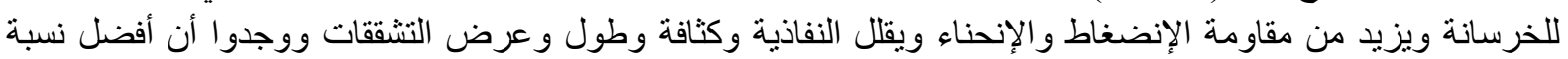

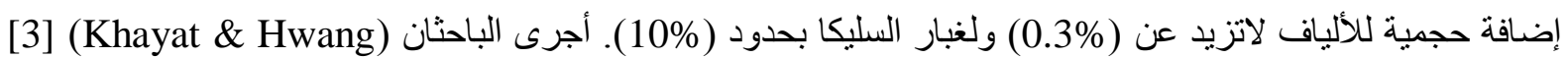

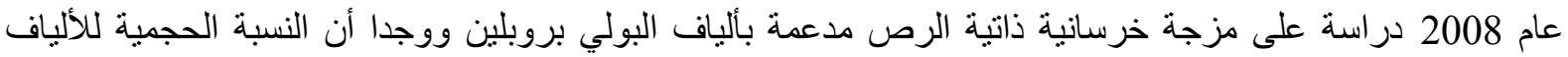

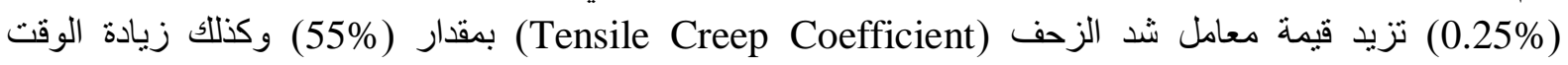
[4] المستغرق لظهور التشققات الناتجة عن إنكماش الجفاف من (5.2) إلى (8.3) يوم. أجرى الباحثان (Chin, Xiao)

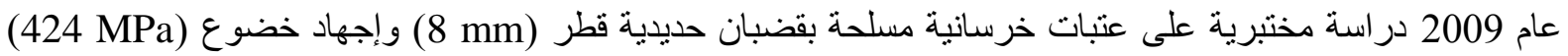

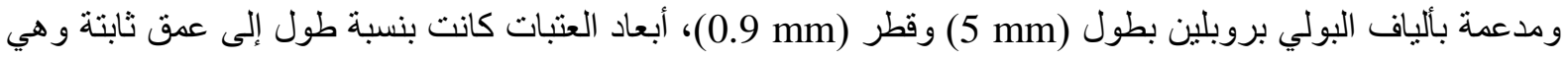

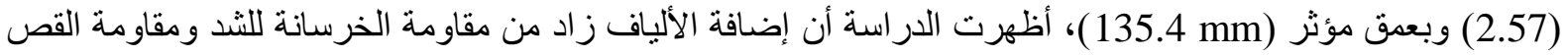

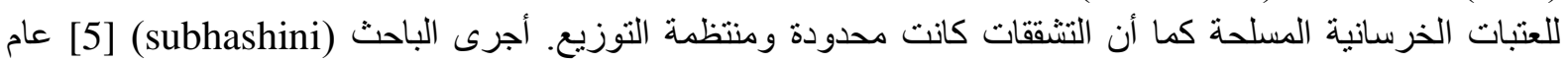

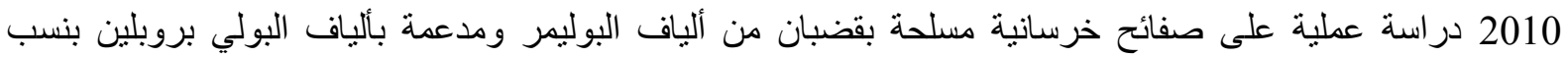

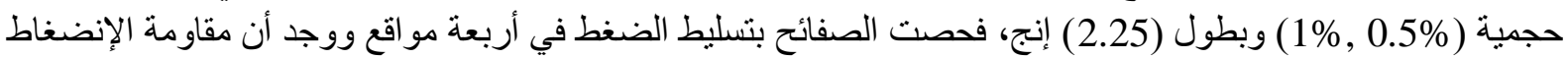
زادت بمقدار (8\%) مقارنةُبالصفائح الخرسانية غير المدعمة بالألياف. أجرى الباحثين ( كاما Fernando \& Gonzalo

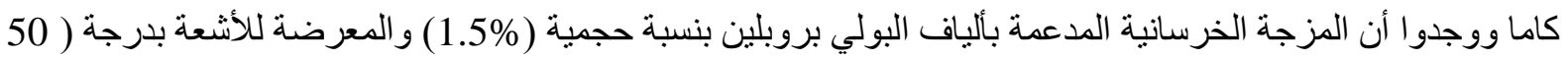

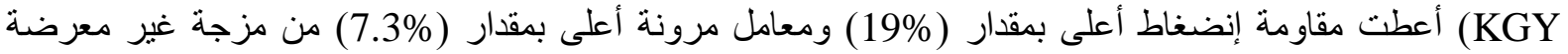

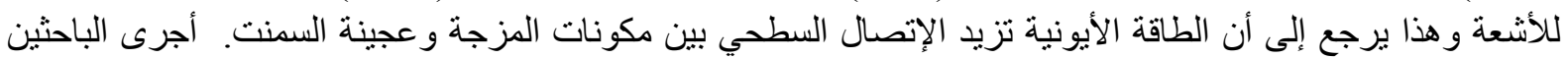

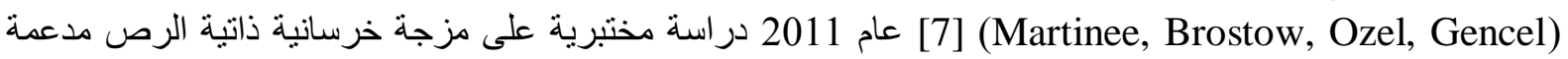

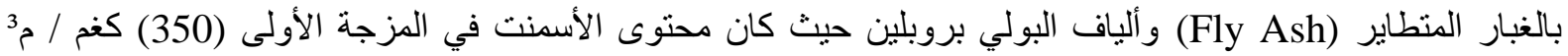

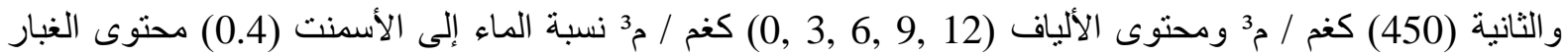

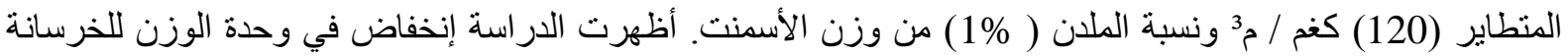
بزيادة كمية الألياف وزيادة في مقاومة الإنضغاط و الإنفلاق و الإنحناء لغاية محتوى الألياف (9) كغم / مجأ. 


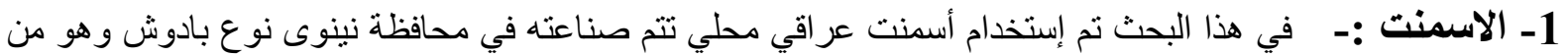

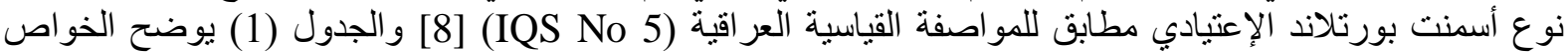

جدول (1) المواصفات الفيزيائية للأسمنت

\begin{tabular}{|c|c|c|}
\hline الفحص & النتيجة & المواصفة (IQS:5/1984) \\
\hline وقت التماسك الإبتدائي (min) & 210 & $45 \mathrm{~min}(\mathrm{Min})$ \\
\hline وقت التماسك النهائي (min) & 330 & $600 \min ($ Max $)$ \\
\hline النعومة (\%) & 5 & $10 \% \quad$ (Max) \\
\hline \multicolumn{3}{|c|}{ مقاومة الإنضغاط (MPa) } \\
\hline 3 Days & 21 & 16 MPa (Min) \\
\hline 7 days & 28.5 & 24 MPa (Min) \\
\hline
\end{tabular}

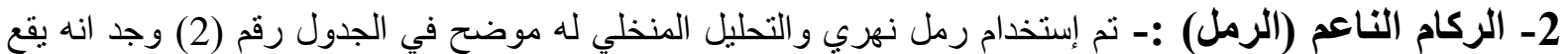

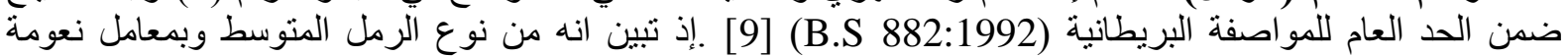

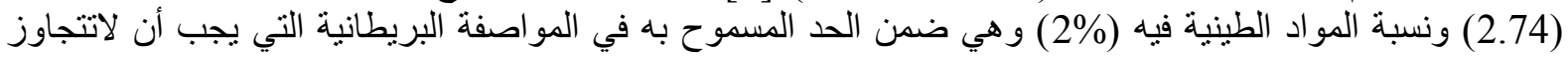

جدول (2) نتائج التحليل المنظلي للرمل

\begin{tabular}{|c|c|c|c|c|c|}
\hline \multirow[t]{2}{*}{ 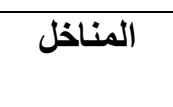 } & \multirow[t]{2}{*}{ المارة \% } & \multirow{2}{*}{$\begin{array}{l}\text { حدود المواصفة \% 882-1992) } \\
\text { (B.S 882) }\end{array}$} & \multicolumn{3}{|c|}{ حدود إضافية (B.S 882-1992) \% } \\
\hline & & & خشن & متوسط & ناعم \\
\hline (No.4) & 100 & $100-89$ & $\begin{array}{ll}---- \\
--\end{array}$ & ------ & ---- \\
\hline (No.8) & 86 & 100-60 & $100-60$ & 100-65 & 100-80 \\
\hline (No.16) & 70 & 100-30 & 100-30 & $100-45$ & 100-70 \\
\hline (No30) & 49 & 100-15 & 54-15 & 80-25 & 100-55 \\
\hline (No.50) & 17 & $70-5$ & $40-5$ & $48-5$ & $70-5$ \\
\hline (No.100) & 4 & 15-0 & ------ & ----- & ----- \\
\hline
\end{tabular}

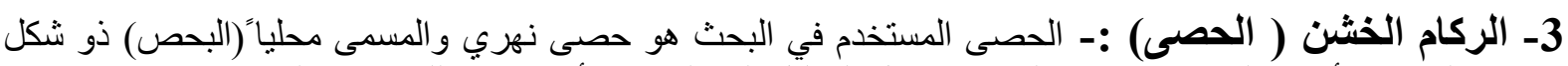

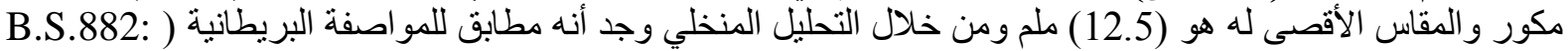

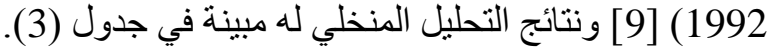
جذول (3) نتائج التحليل المنظلي للحصى (3.S82)

\begin{tabular}{|c|c|c|}
\hline حدود المارة & \% (B.S 882-1992) \\
\hline 12.5 & 97.4 & $90-100$ \\
\hline 10 & 57.4 & $50-85$ \\
\hline 5 & 2.1 & $0-10$ \\
\hline 2.36 & 1 & --- \\
\hline
\end{tabular}

4- الماء :- نم إستخدام ماء الثرب الاعتيادي لمدينة الموصل في الخلطة الخرسانية ومعالجة النماذج وهو ماء صالح ل للشرب وخالي من الشو ائب .

5- ألياف البولي بروبلين :- نم إستخدام ألياف البولي بروبلين نوع (Sika Fiber) شكل (1) بن (1) بنسب حجمية (0.25,0.50,0.75,1.0,1.25) \% على التو الي كما ورد في جدول (6), و الخو اص موضحة في جدول (4).

جدول (4) خواص ألياف البولي برويلين

\begin{tabular}{|c|c|c|c|c|}
\hline شكل المقطع & طول الليف (mm) & مقاومة الثّد & معامل المرونة & 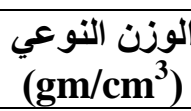 \\
\hline مستطيل & 50 & 350 & $\mathbf{3 5 0 0}$ & 0.91 \\
\hline
\end{tabular}




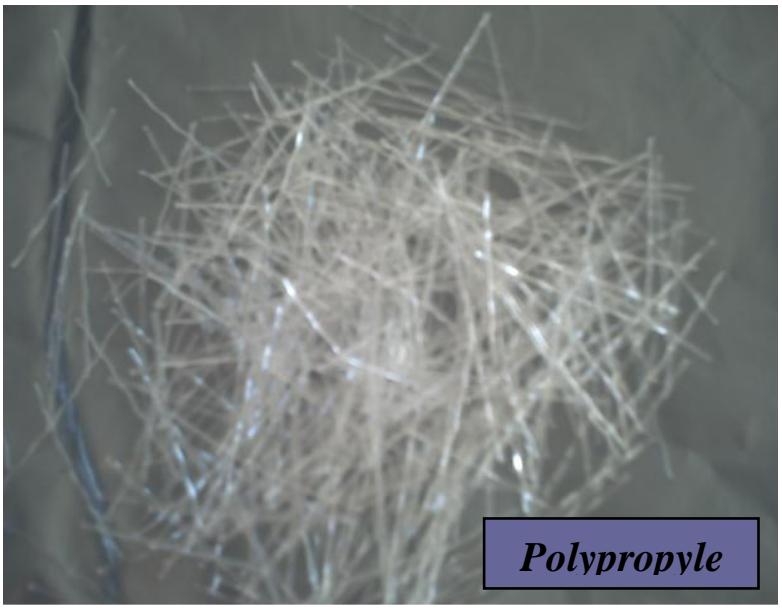

شكل (1) ألياف البولي برويلين المستخدمة في البحث
6- الملان :- الملدن المستخدم ذو أداء عالي من نوع (Hyperplast PC 200)

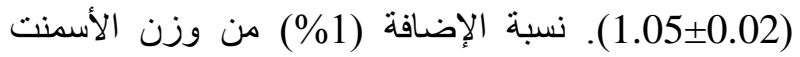
لغرض خفض نسبة الماء إلى الأسمنت وتقليل مشافل الإنل

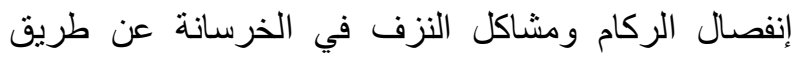

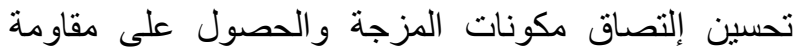

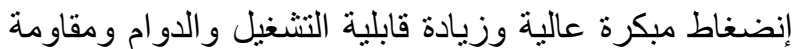
العوامل الجوية وتقليل نفاذية الخرسانة.

\section{طريقة صب وفحص النماذج الخرسانية :-}

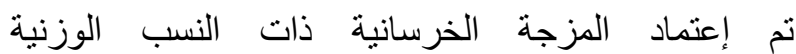
(1:1.5:2/0.35) في هذا البحث. إن عملية صب النبان النماذج تبدأ

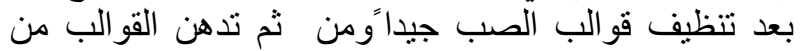

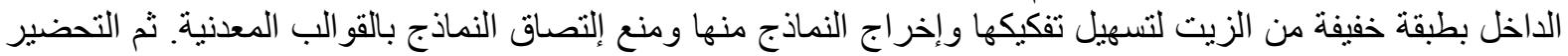

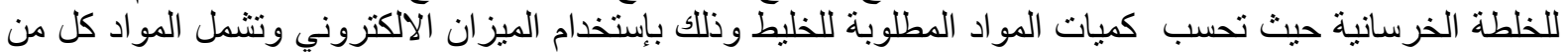

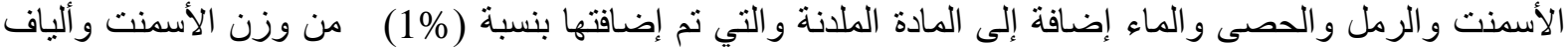

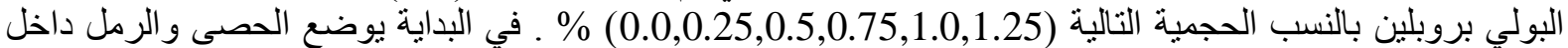

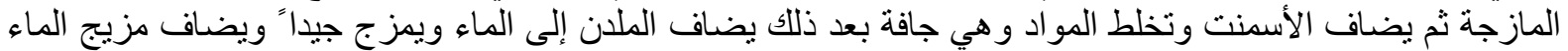

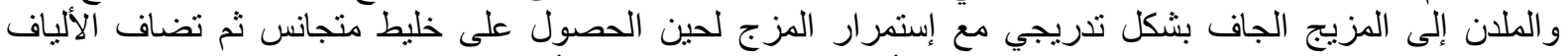

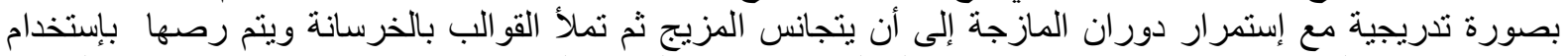

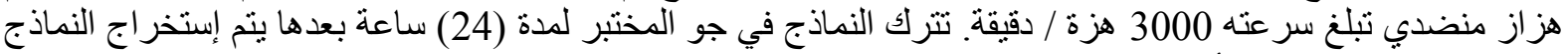

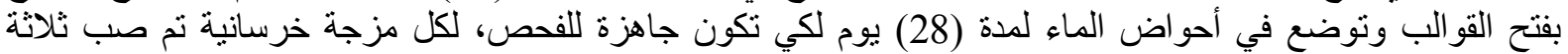

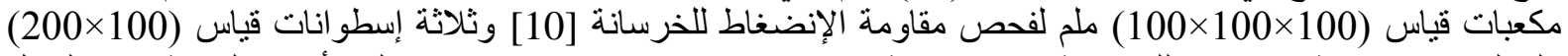

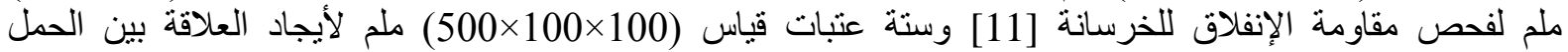

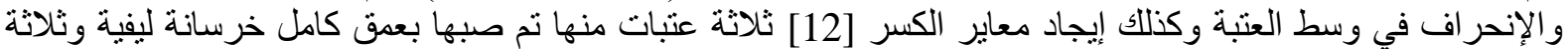

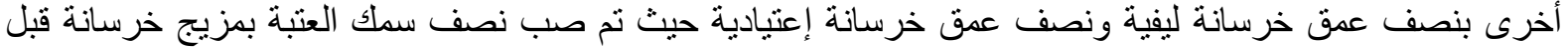

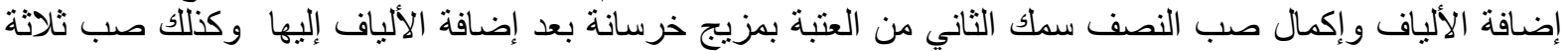

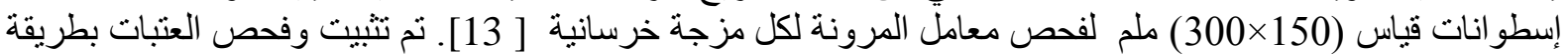
معاير الكسر [12] بتسليط حمل مركزي منفرد (Center-Point Loading) بمعدل ثابت في مركز العنبة وقياس

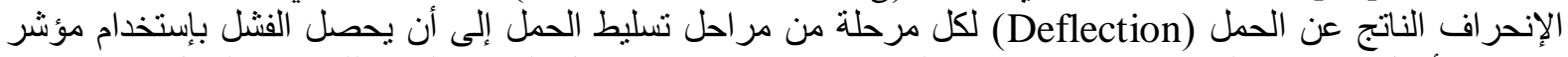

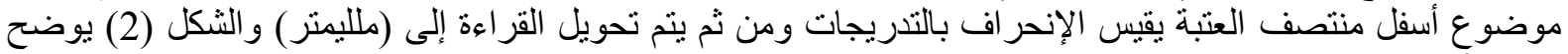

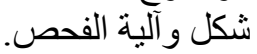
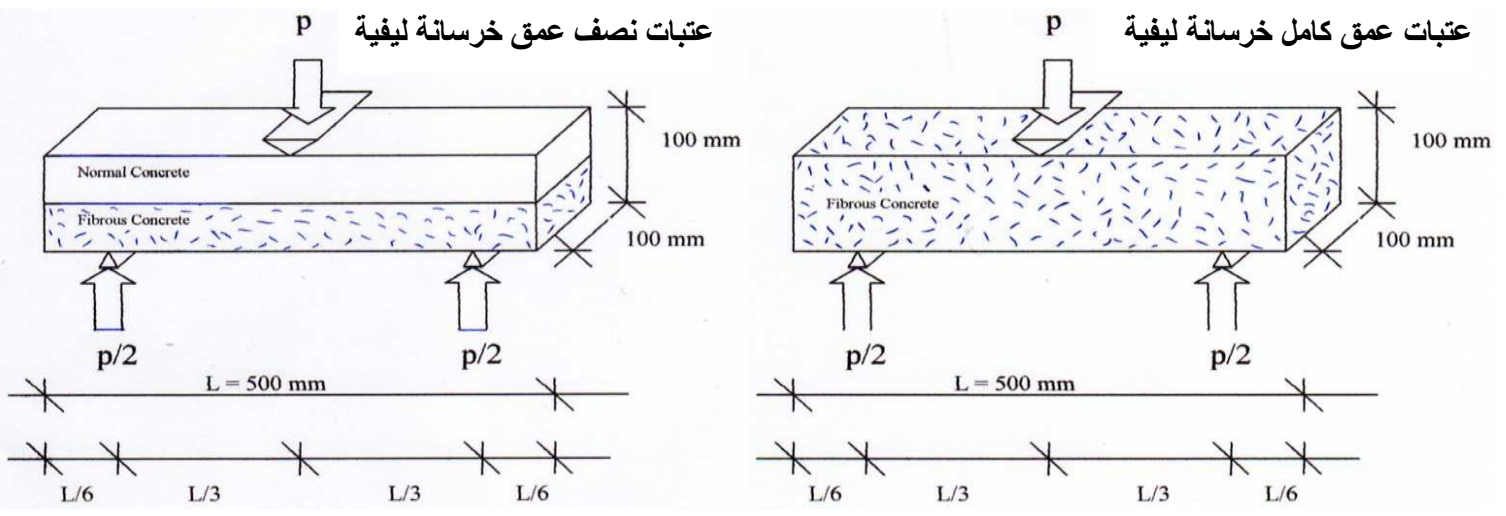

شكل (2) شكل وآلية الفحص 


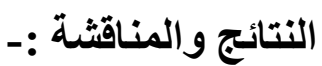

\section{1: (Compressive Strength) مقاومة الإنضغاط}

تم حساب مقاومة الإنضغاط من فحص ثلاثثة مكعبات بأبعاد (100×100×100) ملم لكل مزجة خرسانية (

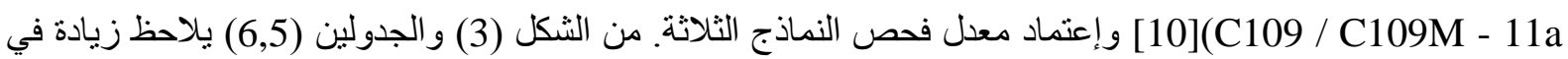

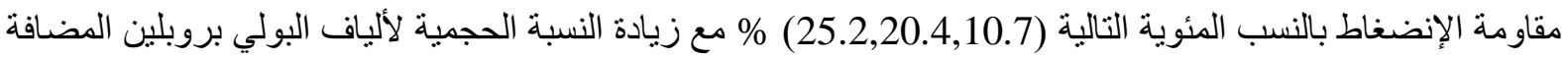

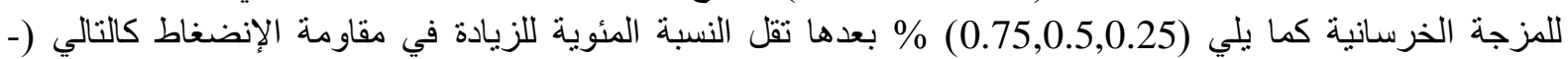

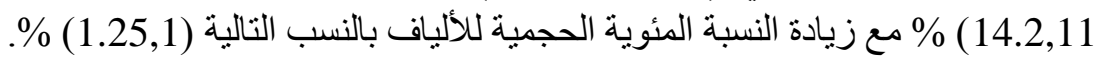

\section{2. مقاومة الإنفلاق (Splitting Strength)}

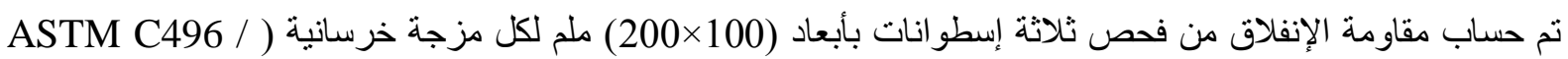
(111] (C496M - 04e1

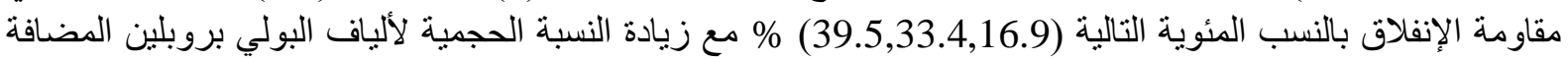

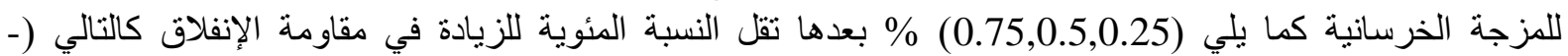
5.1,9.8) \% مع زيادة النسبة المئوية الحجمية للألياف بالنسب التالية (1.25,1)

$$
3
$$

تم قياس قيمة معاير الكسر ومقدار الإنحر اف من خلال فحص ستة عتبات خرسانية بأبعاد (100×100×

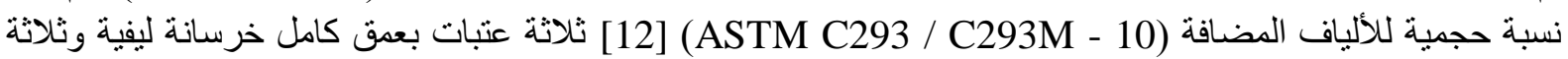

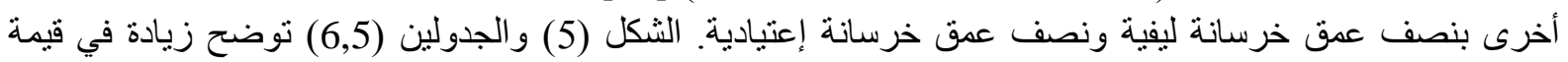
معاير الكسر بالنسب المئوية التالية (52.8,15.2,2.7) \%

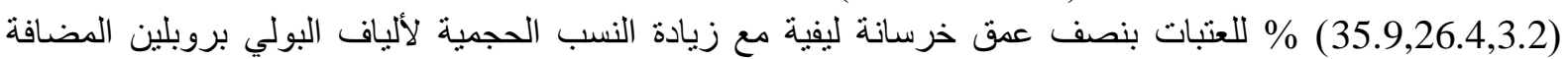

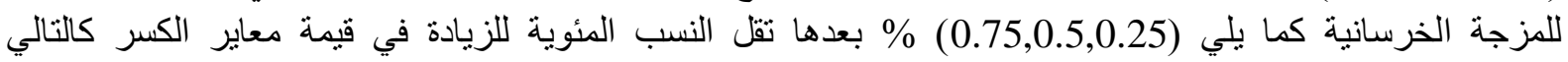

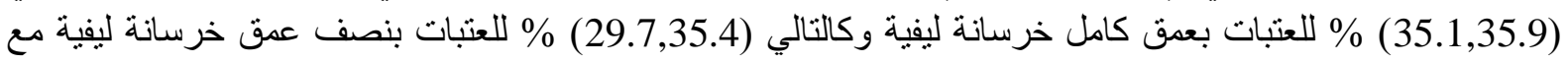

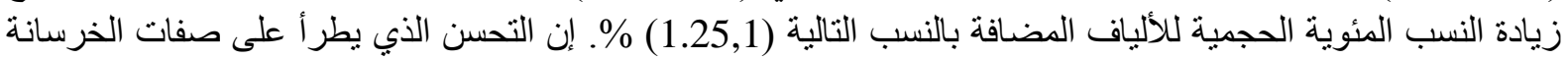

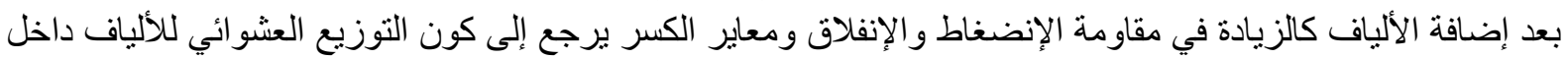

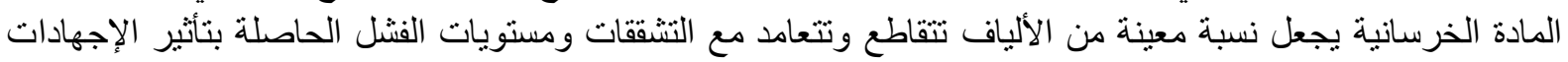

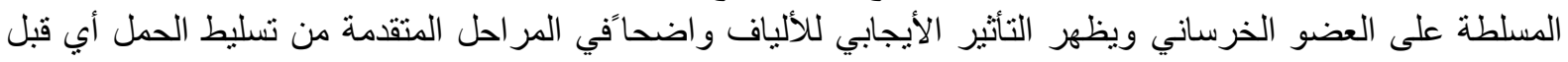

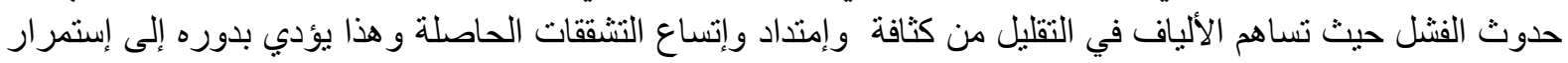

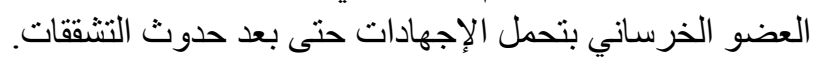

\section{4. (Deflection in Center of Beam) (الإنحراف في مركز العتبة}

تم في هذا البحث قياس وتسجيل الإنحر اف الحاصل في مركز العتبة لكل مرحلة من مر احل تسليط الحمل بإستخدام مؤشر

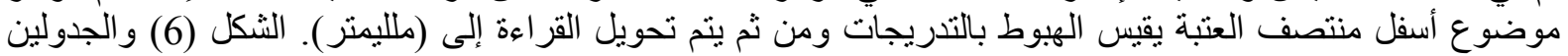

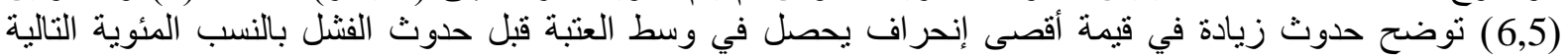
(120,80,40)

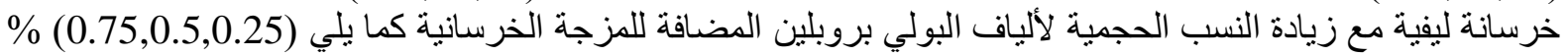

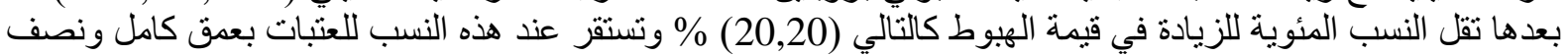

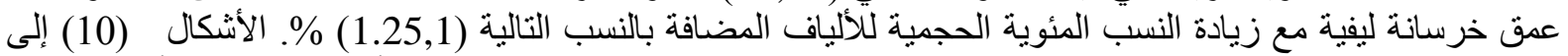

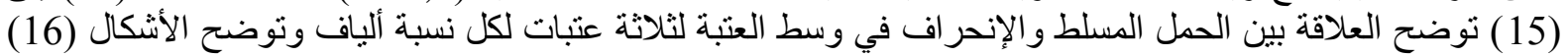

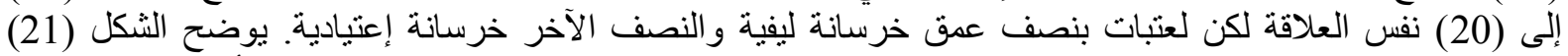

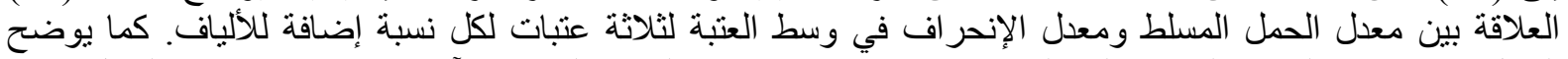

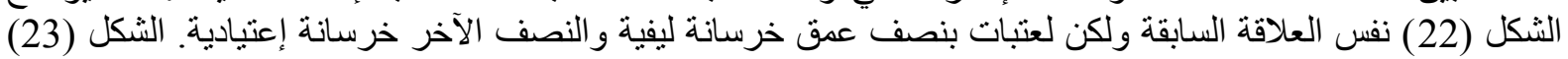




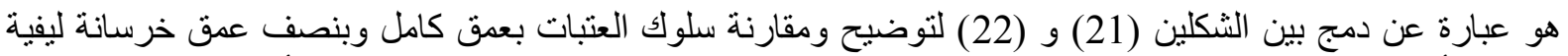

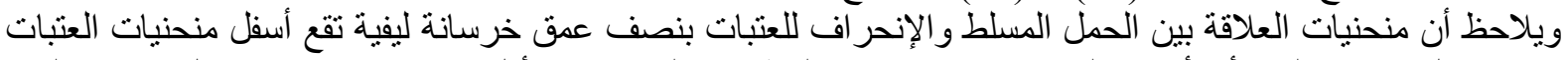
بعمق كامل خر سانة ليفية أب أن قيم المقاومة و الإنحر اف و المطاو عانة التي توفر ها أقل من مثيلاتها بعمق كامل خر سانة ليفية ولنفس النسب الحجمية للألياف في المزجة.

\section{5. : (Modulus of Elasticity) معامل المرونة}

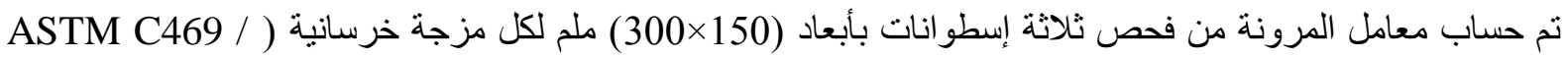

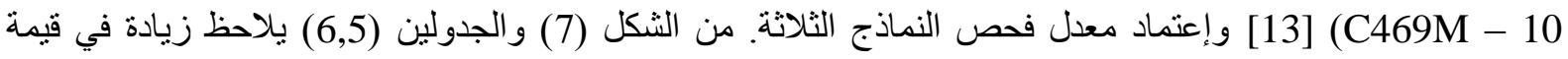
معامل المرونة بالنسب المئوية التالية (10.72,8.9,4.7)

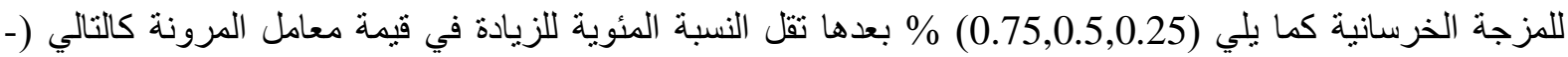

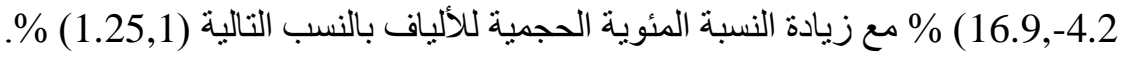

6. العلاقة بين الإجهاد والإنفعال (Relationship Between Stress and Strain) :-

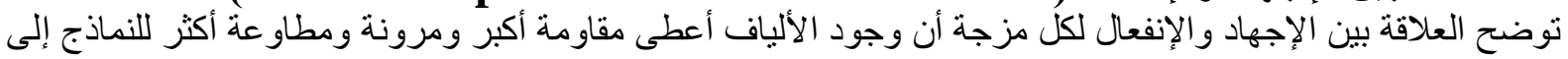

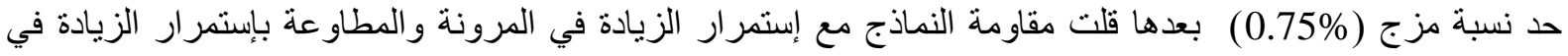

النسبة الحجمية للألياف، الثنكل (8) (8)

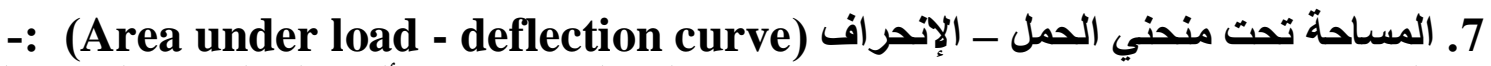
تعد الخرسانة الإعنيادية مادة قصيفة (Brittle Material) ولهذا السبب تضاف الألألياف إلى الخرسانة لتحسين المطيلية (Ductility)

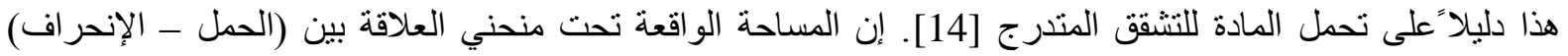

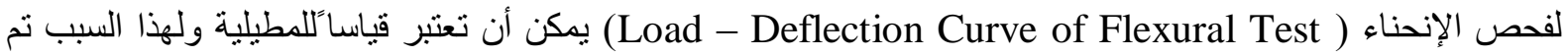

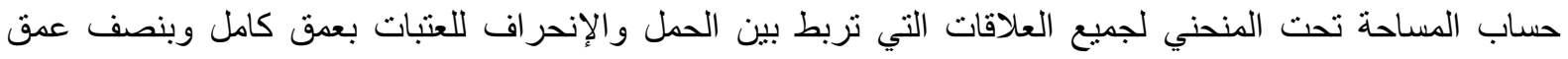
خرسانة ليفية كما في الجدول (7) و الثكل (9) ويلاحظ أن المساحة تحت المنحني تزداد إلى حد نسبة إضافة مئوية

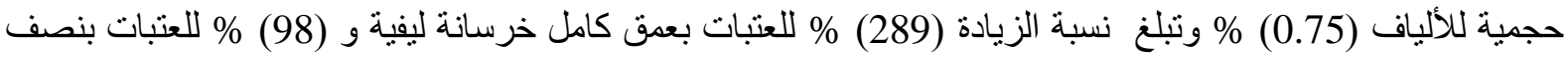
عمق خرسانة ليفية وبعد هذه النسبة تبدأ القيم بالإنخفاض

جدول (5) تغير مواصفات الخرسانة بتغير النسب المئوية الحجمية للألياف المضافة

\begin{tabular}{|c|c|c|c|c|c|c|}
\hline $1.25 \%$ & $1.00 \%$ & $0.75 \%$ & $\mathbf{0 . 5 0} \%$ & $0.25 \%$ & $0.00 \%$ & النسب المئوية الحجمية للألياف \\
\hline 27.56 & 35.67 & 40.24 & 38.70 & 35.56 & 32.13 & مقاومة الإنضغاط ( N/mm²) \\
\hline 2.81 & 3.25 & 4.13 & 3.95 & 3.46 & 2.96 & مقاومة الإنفلاق (MPa) \\
\hline 17.89 & 20.64 & 23.75 & 23.47 & 22.55 & 21.54 & معامل المرونة ( GPa ) \\
\hline 4.96 & 4.99 & 5.61 & 4.23 & 3.77 & 3.67 & معاير الكسر للعتبات بعق كامل خرسائة ليفية (MPa) \\
\hline 0.6 & 0.6 & 1.1 & 0.9 & 0.7 & 0.5 & الإنحراف للعتبات بعمق كامل خرسائة ليفية (mm) \\
\hline 4.76 & 4.97 & 4.99 & 4.64 & 3.79 & 3.67 & معاير الكسر للعتبات بنصف عمق خرسائة ليفية (MPa) \\
\hline 0.6 & 0.6 & $\mathbf{1 . 0}$ & 0.9 & 0.6 & 0.5 & الإنحراف للعتبات بنصف عمق خرسانة ليفية (mm) \\
\hline
\end{tabular}

جدول (6) النسب المئوية للزيادة والنقصان في مواصفات الخرسانة بتغير النسب المئوية الحجمية للألياف المضافة

\begin{tabular}{|c|c|c|c|c|c|c|}
\hline $1.25 \%$ & $1.00 \%$ & $0.75 \%$ & $0.50 \%$ & $0.25 \%$ & $0.0 \%$ & النسب المئوية الحجمية للألياف \% \\
\hline-14.22 & 11.01 & 25.24 & 20.44 & 10.67 & 0.00 & نسب الزيادة والنقصان في مقاومة الإنضغاط \% \\
\hline-5.06 & 9.79 & 39.52 & 33.44 & 16.89 & 0.00 & نسب الزيادة و النقصان في مقاومة الإنفلاق \% \\
\hline-16.94 & -4.17 & $\mathbf{1 0 . 2 5}$ & 8.96 & 4.68 & $\mathbf{0 . 0 0}$ & نسب الزيادة والنقصان في معامل المرونة \% \\
\hline 35.14 & 35.96 & 52.86 & 15.25 & 2.72 & $\mathbf{0 . 0 0}$ & نسب التغير في معاير الكسر للعتبات بعقى كامل خرسانة ليفية \% \\
\hline 20.00 & 20.00 & 120.00 & 80.00 & 40.00 & 0.00 & نسب التغير في الإحراف للعتبات بعمق كامل خرساتة ليفية \\
\hline 29.70 & 35.42 & 35.96 & 26.43 & 3.26 & 0.00 & نسب التغير في معاير الكسر للعتبات بنصف عمق خرساتة ليفية \% \\
\hline 20.00 & 20.00 & 100 & 80.00 & 20.00 & $\mathbf{0 . 0 0}$ & نسب التغير في الإنحراف للعتبات بنصف عمق خرسانة ليفية \% \\
\hline
\end{tabular}



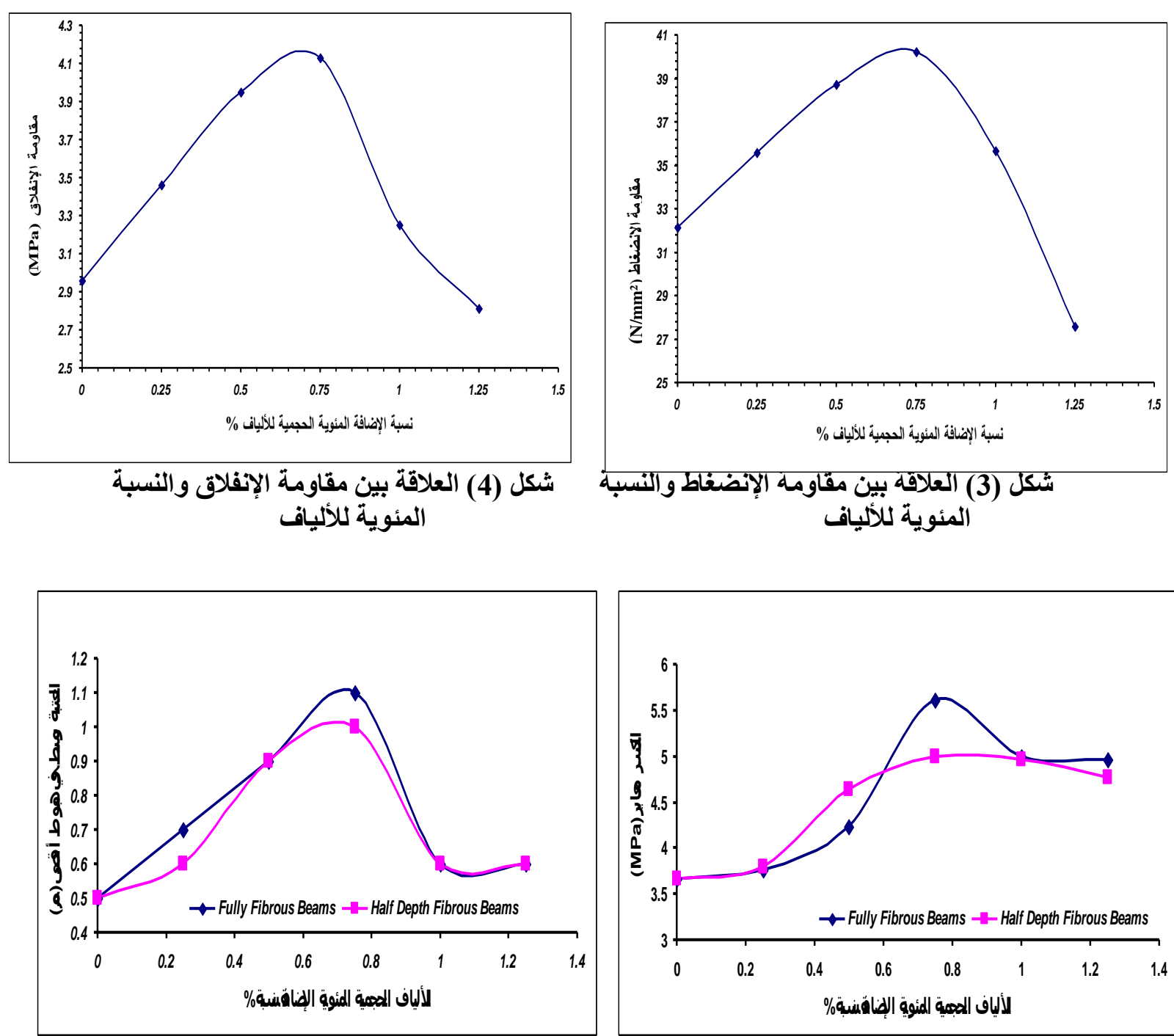

المئوية للألياف

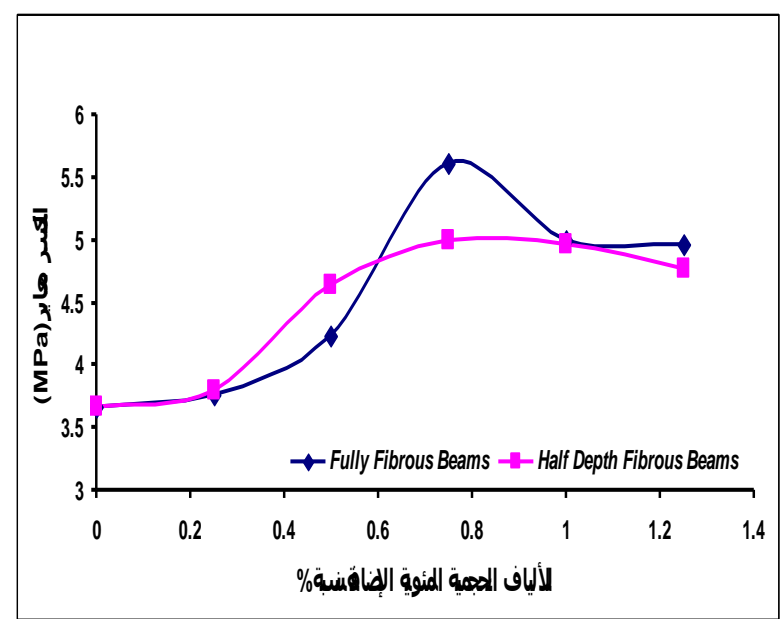

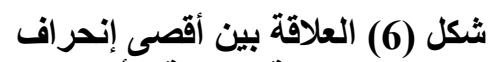
والنسبة المئوية للألياف إنماف

شكل (5) العلاقة بين معاير الكسر

و النسبة المئوية للألياف النف

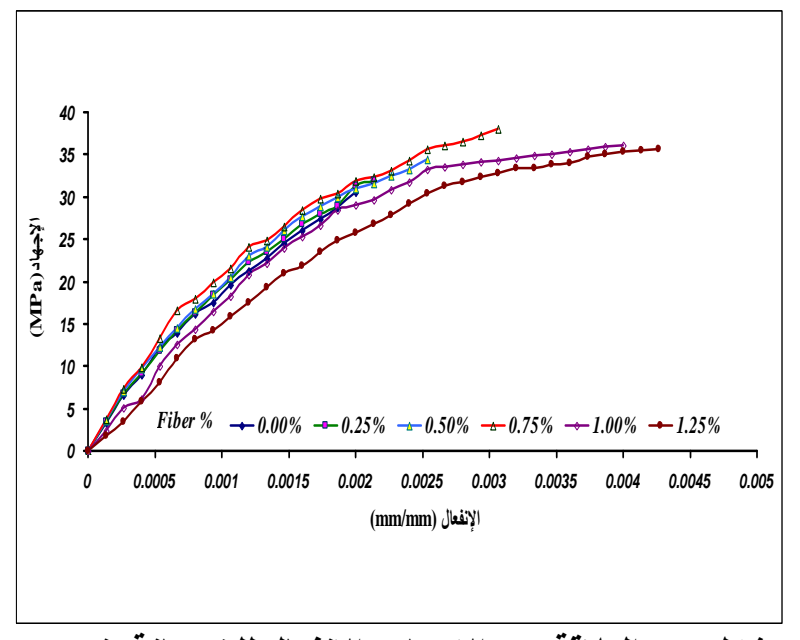

شكل (8) العلاقة بين الاجهاد والانفعال للخؤسانة بنسب ل ل واضافة المئوية حجمية مختلفة للألياف الأفعال

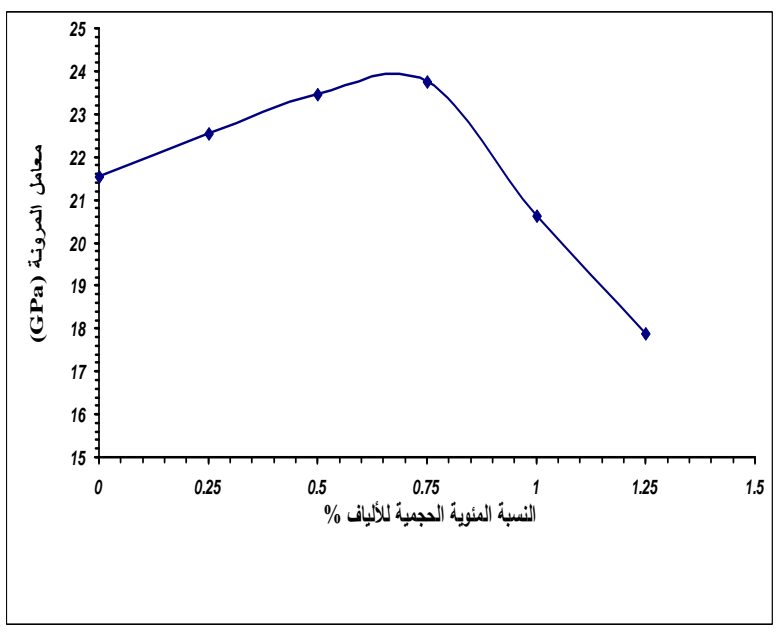

شكل (7) العلاقة بين معامل المرونة ونسبة الإضافة المئوية الحجمية للألياف 
جدول(7): تغيير قينة المساحة تحت منخني العلاقة بين الحمل وألانحراف للعتبات بتغبير النسب المئوية للألياف المضافة

\begin{tabular}{|c|c|c|c|c|c|c|}
\hline $\begin{array}{c}1.25 \\
\%\end{array}$ & $\begin{array}{c}1.00 \\
\%\end{array}$ & $\begin{array}{c}0.75 \\
\%\end{array}$ & $\begin{array}{c}0.50 \\
\%\end{array}$ & $\begin{array}{c}0.25 \\
\%\end{array}$ & $\begin{array}{c}0.00 \\
\%\end{array}$ & النسبة المئوية الحجمية للألياف في المزجة \\
\hline 5.35 & 5.9 & 12.6 & 7.38 & 4.82 & 3.24 & 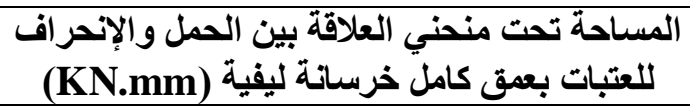 \\
\hline 4.89 & 4.99 & 6.42 & 5.73 & 4.22 & 3.24 & 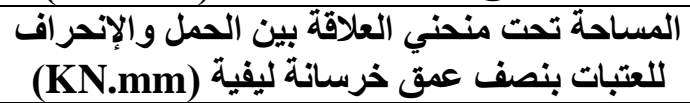 \\
\hline 65 & 82 & 289 & 128 & 49 & $\mathbf{0 . 0}$ & 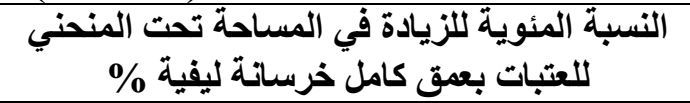 \\
\hline 51 & 54 & 98 & 77 & 30 & 0.0 & 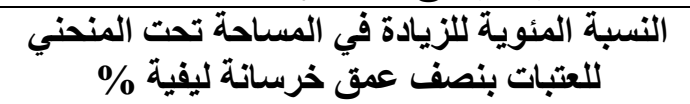 \\
\hline
\end{tabular}

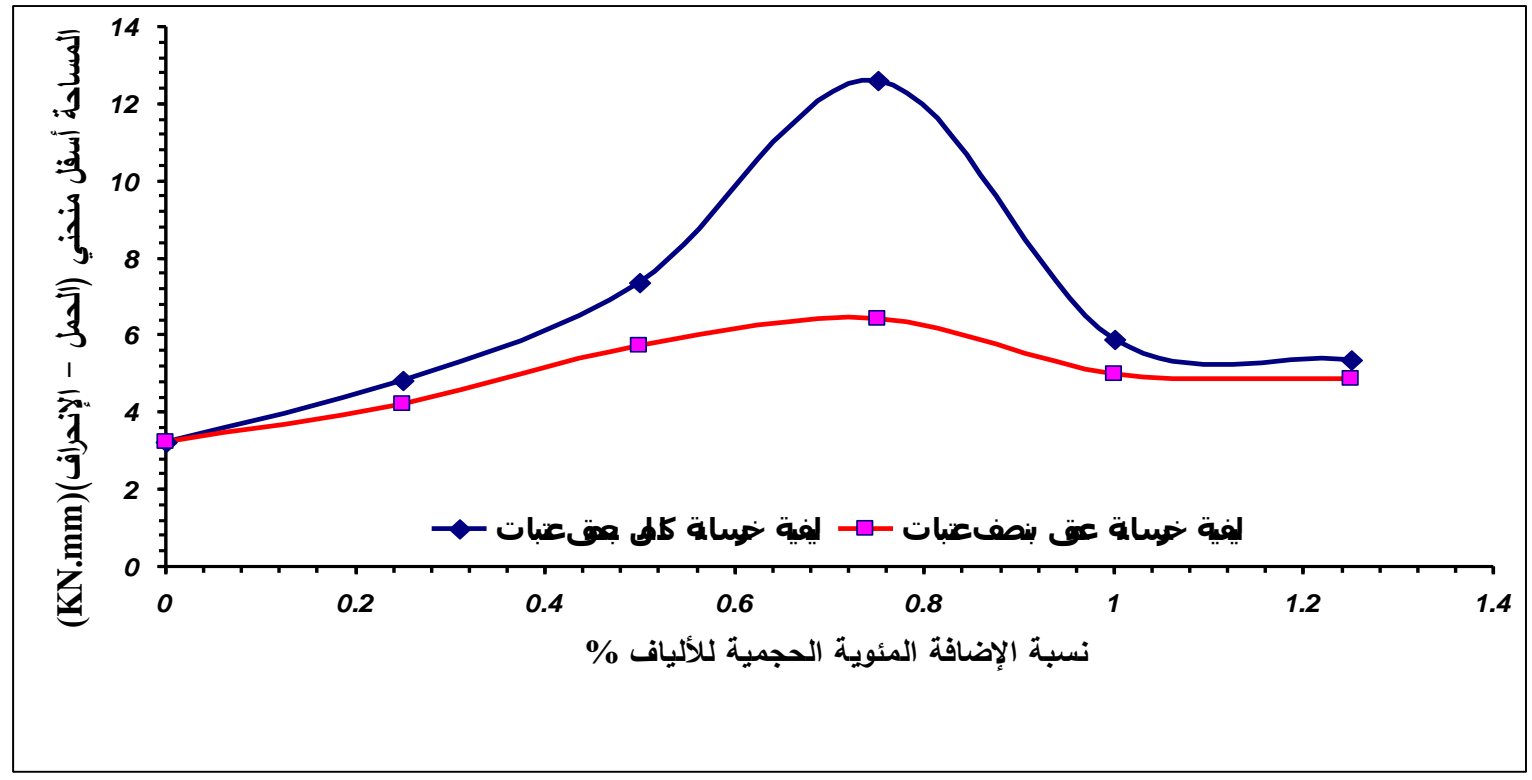

شكل (9) العلاقة بين المساحة أسفل منحني (الحمل - الإنحراف) والنسبة المئوية الحجمية للألياف للعتبات بعمق كامل ونصف عمق العمل خرساتة ليفية

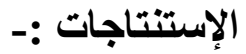

1- دن خلال النتائج العملية المستحصلة من هذا البحث يلاحظ تحسن صفات الخرسانة بإضـافة ألياف البولي بروبلين إليها بنسب إضـافة مئويـة حجمية مختلفة و إن أفضل نسبة إضـافة للألياف كانت (5 \%

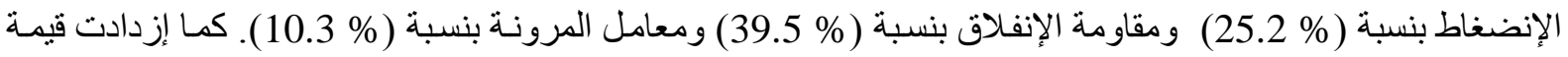

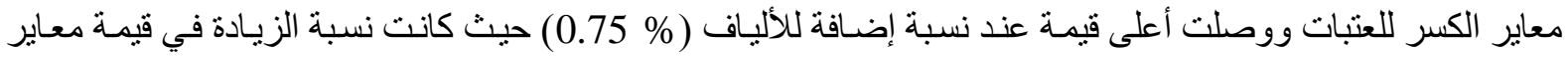

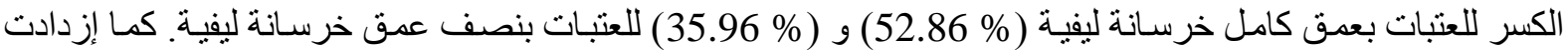

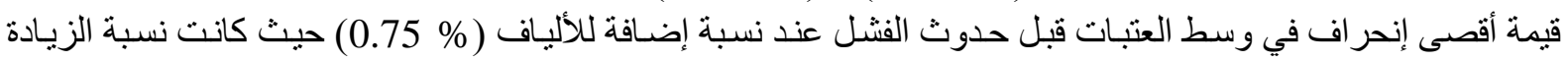
(120\%) للعتبات بعمق كامل خرسانة ليفية و ( 100 1) للعتبات بنصف عمق خرسانة ليفية.

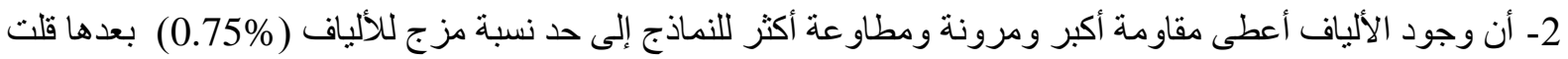

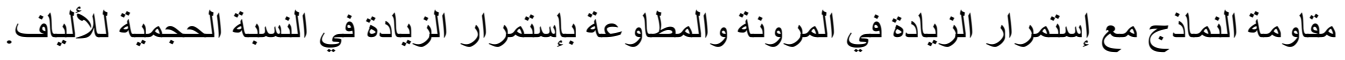

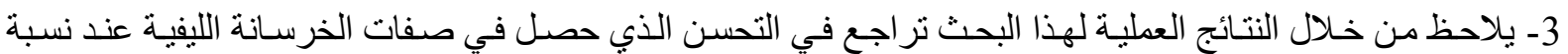

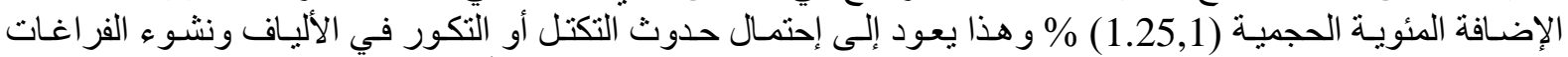

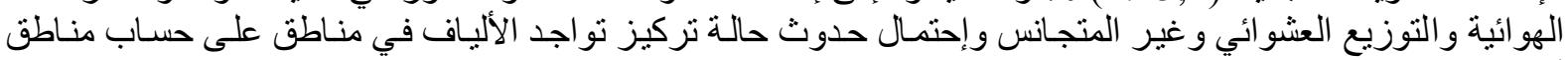
أخرى داخل الخرسانة. 


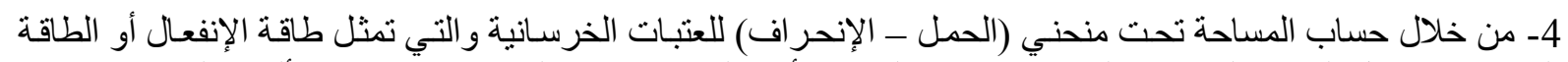

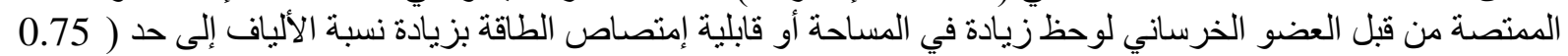

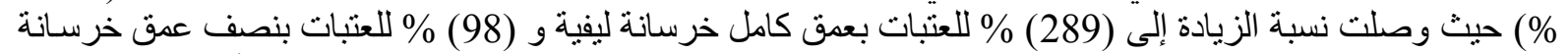

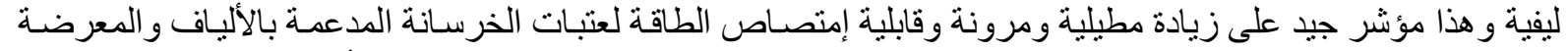

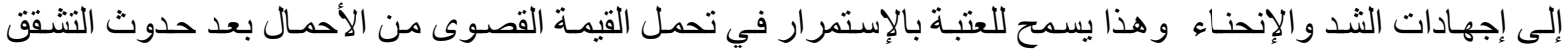
و السماح للخرسانة بتحمل أقصى حمل صممت من أجله.

5- بالنسبة للعتبات بنصف عمق خرسانة ليفية لوحظ أن المساحة تحت منحني الحمل الإنحر اف كانت أقل من مثيلاتها من

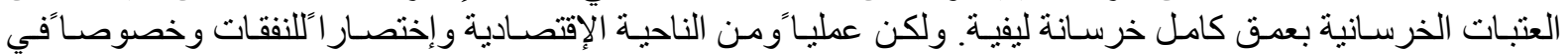

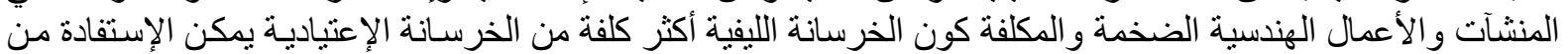

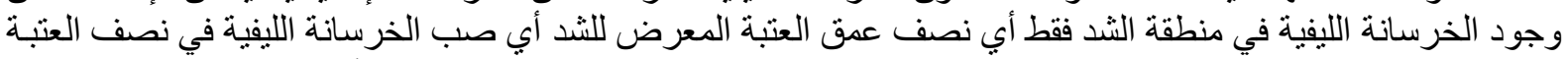

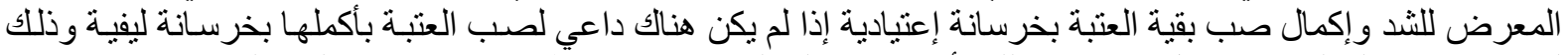

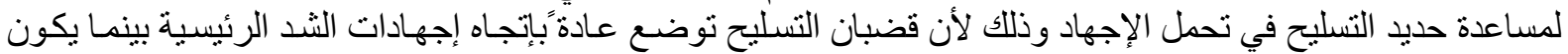

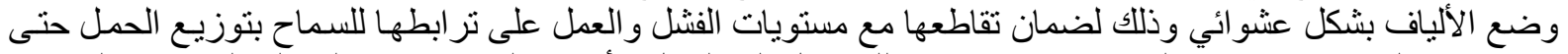

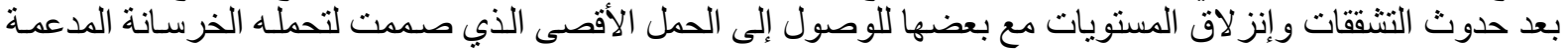
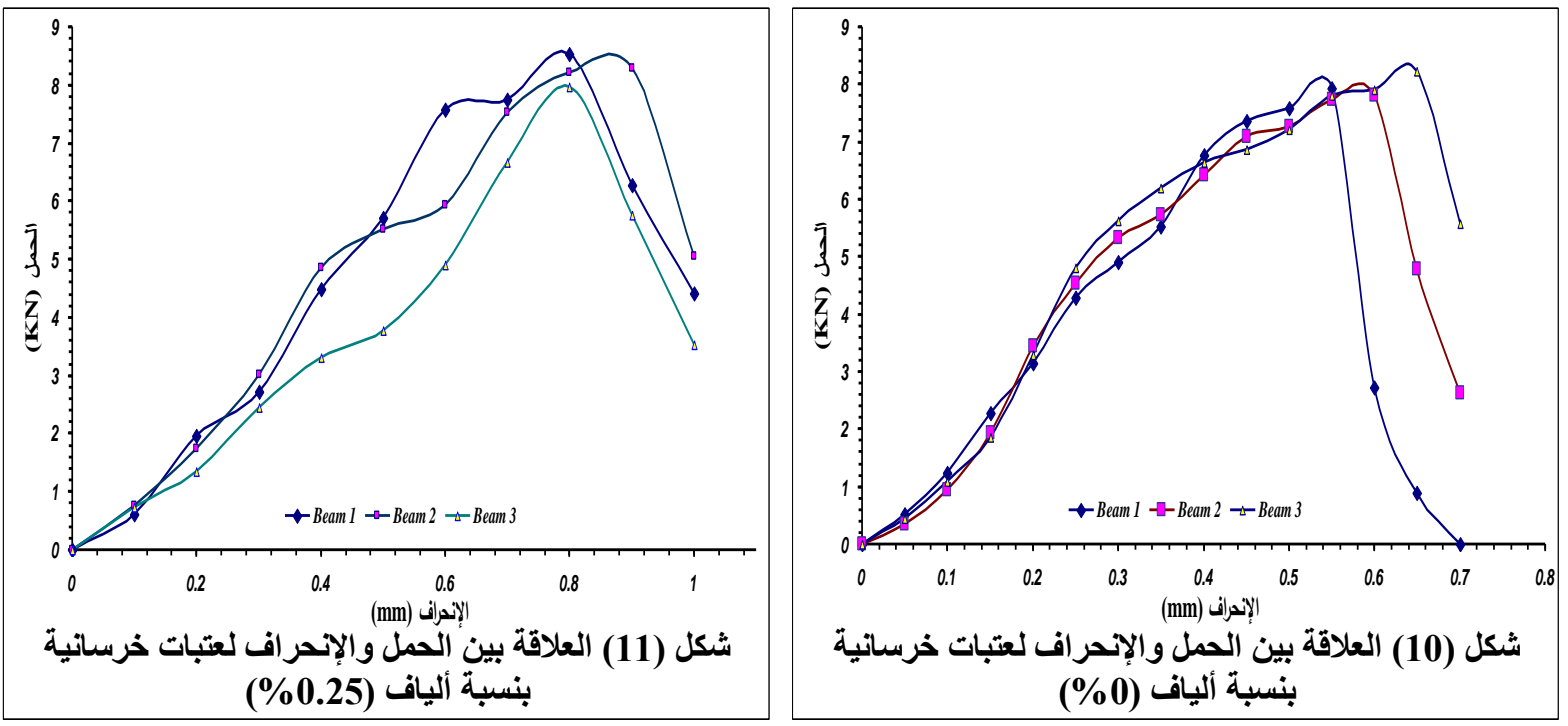

شكل (10) العلاقة بين الحمل والإنحراف لعتبات خرسانية بنسبة ألياف (\%0)

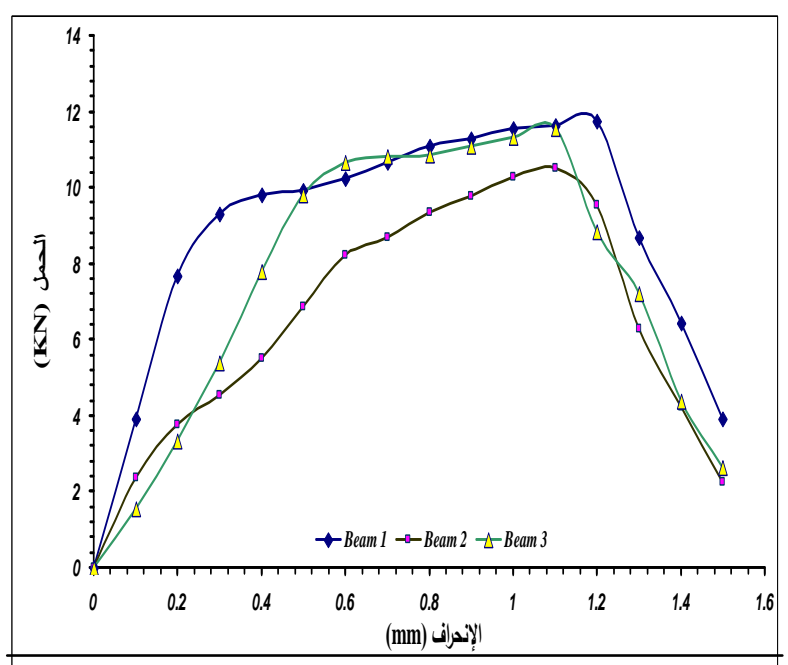

شكل (13) العلاقة بين الحمل والإنحراف لعتبات

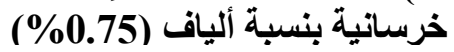

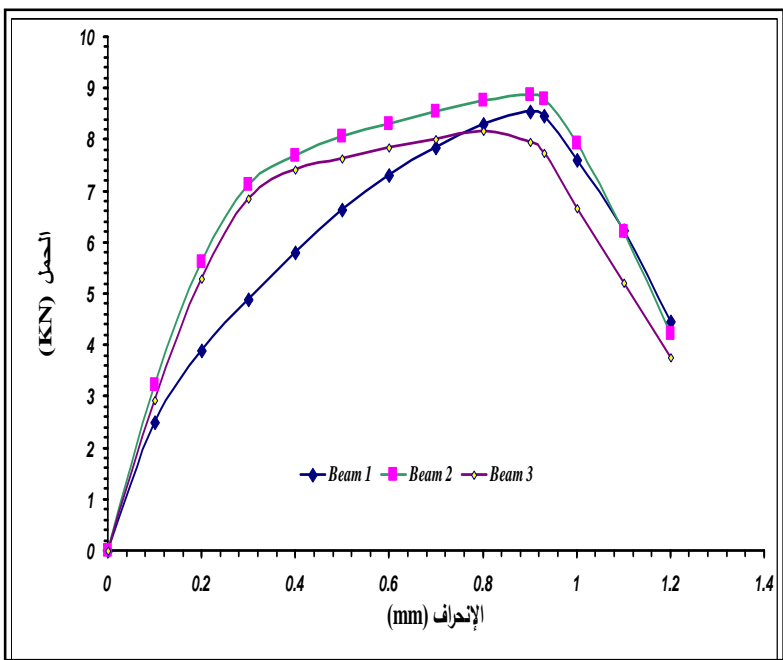

شكل (12) العلاقة بين الحمل والإنحر اف لعتبات خرسانية

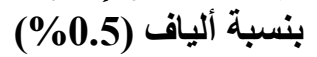



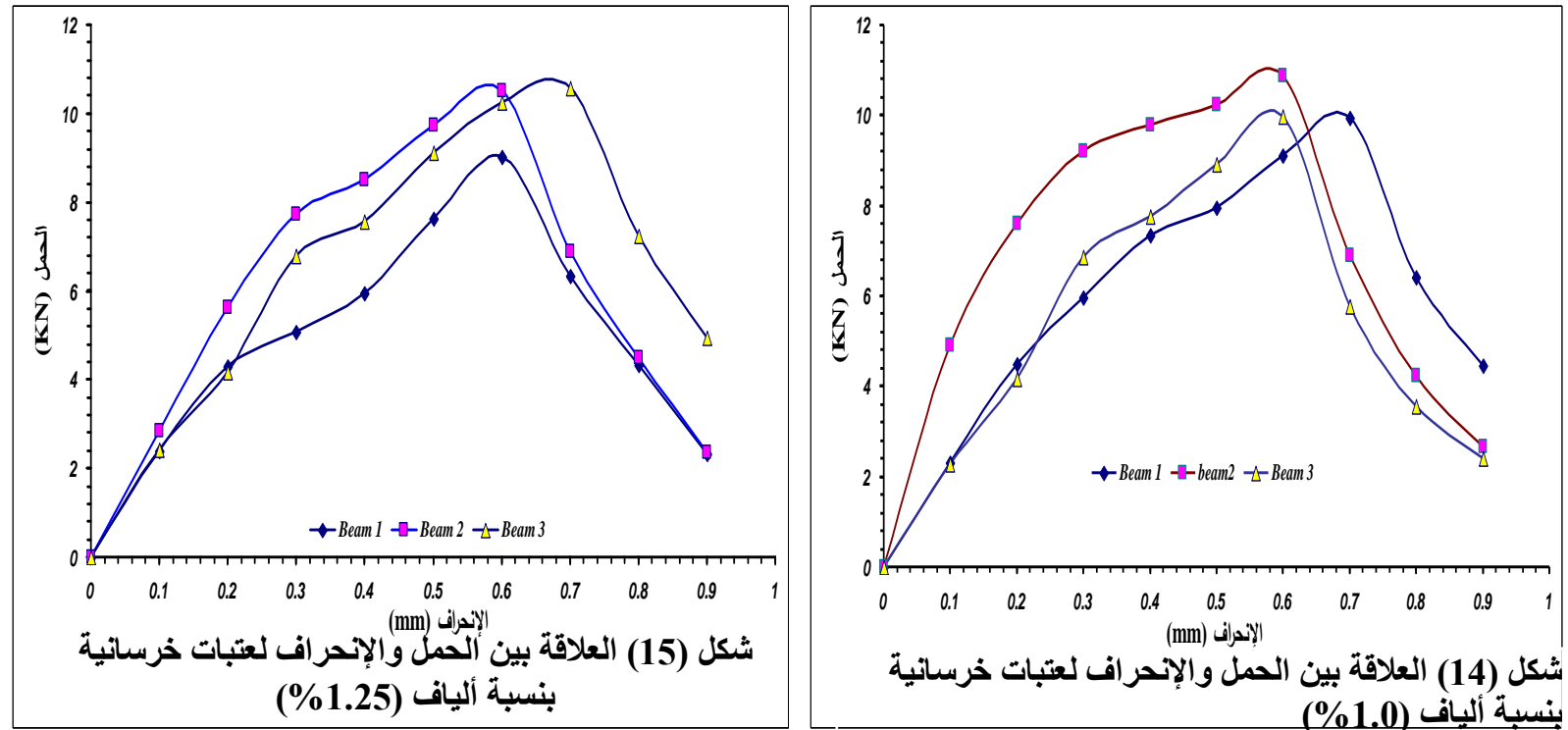

شكل (14) العلاقة بين الحمل والإنحر اف لعتبات خرساتية

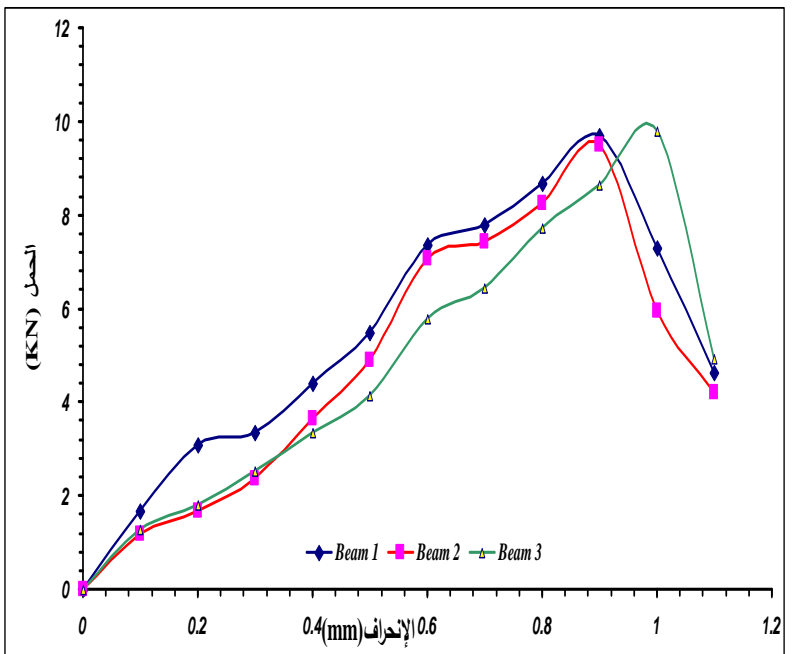

شكل (17): العلاقة بين الحمل والانخر اف لعتبات

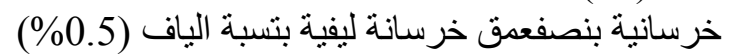
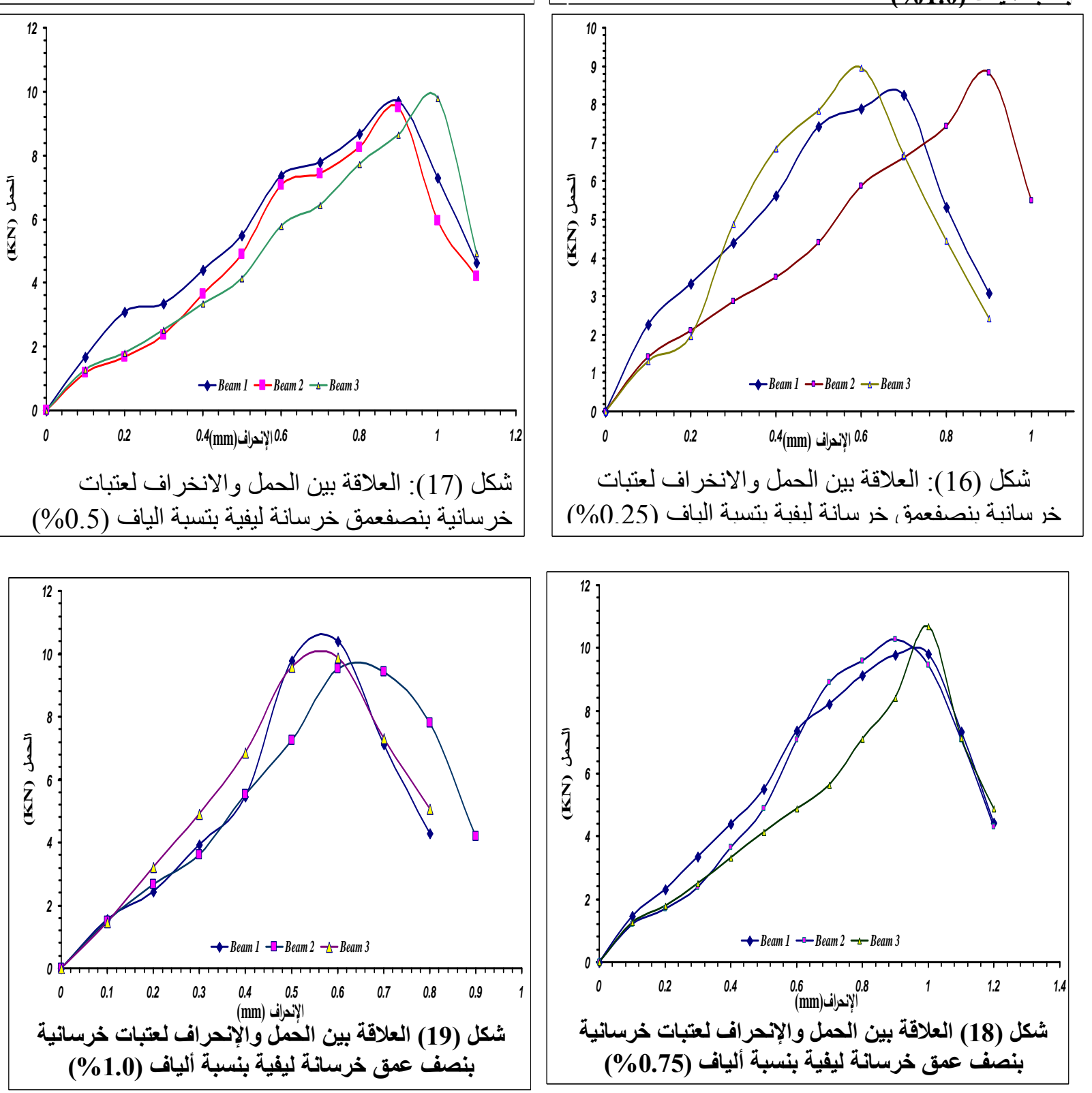

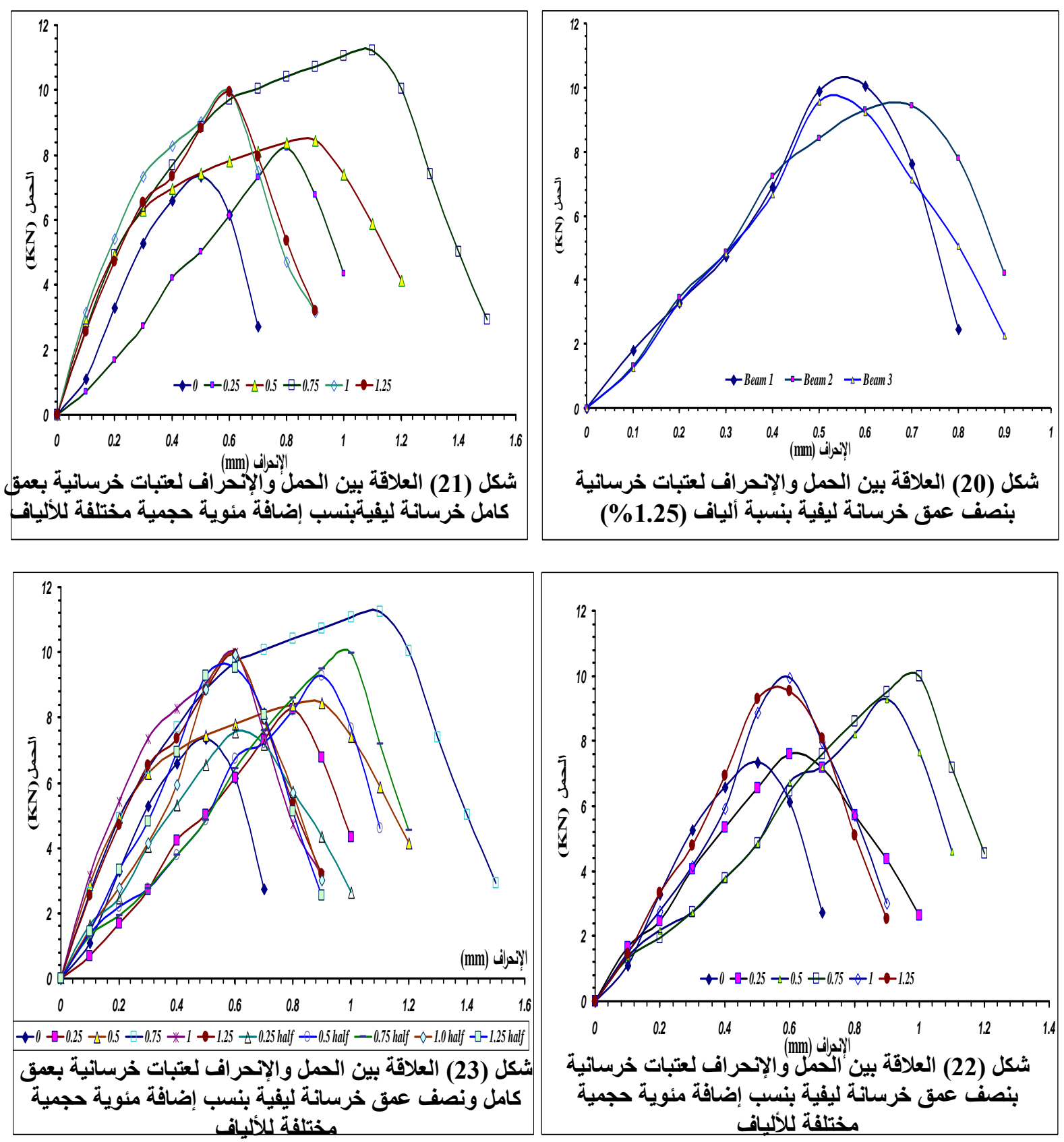

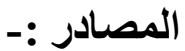

1. Guirguis, B. E. and Potter, R. J., " Polypropylene Fibers in Concrete”, Technical Report TR/F90, Cement and Concrete Association of Australia, 1985.

2. Ezzat, Mohamed, May, “Polypropylene Fiber and Silica Fume Concrete for Bridge Overlays", Paper Submitted for Presentation and Publication in the 82 nd Annual Meeting of the Transportation Research Board, January $12_{\mathrm{th}}-16_{\mathrm{th}}, 2003$, Washington, D. C.

3. Soo-Duck Hwang and Kamal H. Khayat, "Effect of Mixture Composition on Restrained Shrinkage Cracking of Self-Consolidating Concrete Used in Repair", ACI Materials Journal, Technical Paper, Title No. 105-M58, September-October 2008. 
4. C. S. Chin, R. Y. Xiao, "Experimental and Computational Analysis of Fiber Reinforced Concrete Beams", Non-conventional Materials and technologies-September 2009, Bath, UK.

5. Subhashini Neela, "Flexural Behavior of Basalt FRB Bar Reinforced Concrete Members with and without Polypropylene Fiber ", A Thesis Presented to The Graduate Faculty of The University of Akron, Ohio, USA, December, 2010.

6. Gonzalo, Fernando, Osman, Witold, " Mechanical properties of polypropylene-fiber reinforced concrete after gamma irradiation", University of North Texas, Denton, USA, Accepted 26 January 2011.

7. Martinee, Brostow, Ozel,Gencel, “ Mechanical Properties of Self-Compacting Concrete Reinforced with Polypropylene Fibers", Materials Research Innovations, 2011, Vol 15, No 3.

8. IQS No:5, 1984 "Characteristics of OPC" Central Agency for standardization and quality control, Iraq,1984.

9. British Standards Institute, B.S 882-1992 "Aggregates from Natural Sources for Concrete".

10. ASTM C109 / C109M -11a Standard Test Method for Compressive Strength of Hydraulic Cement Mortars Cube Specimens (Using 2-in. or [50 mm]).

11. ASTM C496 / C496M - 04e1 Standard Test Method for Splitting Tensile Strength of Concrete Cylindrical Specimens.

12. ASTM C293 / C293M - 10 Standard Test Method for Flexural Strength of Concrete (Using Simple Beam With Center-Point Loading).

13. ASTM C469 / C469M - 10 Standard Test Method for Static Modulus of Elasticity and Poisson's Ratio of Concrete in Compression.

14. David Roylance, "STRESS-STRAIN CURVES", Department of Materials Science and Engineering Massachusetts Institute of Technology Cambridge, MA 02139August 23, 2001.

تم اجراء البحث في كلية ألهنسة = جامعة ألموصل 